\title{
Prevalência de dores osteomusculares em ciclistas: uma revisão sistemática
}

\author{
Prevalence of musculloskeletal pain in cyclists: a systemic review \\ Prevalencia del dolor musculoesqueléticas en ciclistas: una revisión sistemática
}

Recebido: 09/11/2021 | Revisado: 16/11/2021 | Aceito: 17/11/2021 | Publicado: 19/11/2021

\author{
Sthefane Brito Carneiro \\ ORCID: https://orcid.org/0000-0001-7215-4402 \\ Centro Universitário da Amazônia, Brasil \\ E-mail: sthefanebrito60@gmail.com \\ Marcos Paulo Gama da Costa \\ ORCID: https://orcid.org/0000-0001-6003-8308 \\ Centro Universitário da Amazônia, Brasil \\ E-mail: marcosp.gamacosta@gmail.com \\ Paulo Tavares da Silva Filho \\ ORCID: https://orcid.org/0000-0001-8431-4717 \\ Centro Universitário da Amazônia, Brasil \\ E-mail: paulo-filho9@hotmail.com \\ Indiara de Alencar \\ ORCID: https://orcid.org/0000-0003-3204-3278 \\ Centro Universitário da Amazônia, Brasil \\ E-mail: indiara.alencarstm@gmail.com
}

\begin{abstract}
Resumo
O ciclismo é uma das atividades mais populares ao redor do mundo e apesar de ser considerada uma modalidade de baixo impacto, alguns estudos apontam que uma postura inadequada ou a falta de preparação dos atletas para essa prática incidem em lesões e dores osteomusculares. Nesse sentido objetivou-se verificar a partir de uma revisão sistemática da literatura a prevalência de dores osteomusculares em praticantes de ciclismo a partir dos estudos encontrados em bancos de dados on-line, publicados nos últimos dez anos. Constitui-se um estudo exploratório, qualitativo, do tipo revisão sistemática. Para coleta de dados empregou-se a metodologia Proknow-C e para análise dos resultados optou-se pela análise descritiva. Os resultados indicam alta prevalência de dor entre os ciclistas, sendo comum dores na coluna lombar, joelhos e membros superiores e inferiores. Ressaltando a importância da Fisioterapia no tratamento e prevenção de sintomas dolorosos que podem ser agravados pela falta de assistência especializada e de exercícios preventivos.
\end{abstract}

Palavras-chave: Dores osteomusculares; Atletas de ciclismo; Ciclismo; Fisioterapia.

\begin{abstract}
Cycling is one of the most popular activities around the world and despite being considered a modality of low impact, some studies indicate that an inadequate posture or lack of preparation of athletes for this practice lead to musculoskeletal injuries and pain. In this sense, the objective was to verify, from a systematic literature review, the prevalence of musculoskeletal pain in cycling practitioners based on studies found in online databases, published in the last ten years. It is an exploratory, qualitative study, of the systematic review type. For data collection, the Proknow-C methodology was used and for the analysis of the results, descriptive analysis was chosen. The results indicate a high prevalence of pain among cyclists, with pain in the lumbar spine, knees and upper and lower limbs being common. Emphasizing the importance of Physiotherapy in the treatment and prevention of painful symptoms that can be aggravated by the lack of specialized assistance and preventive exercises.
\end{abstract}

Keywords: Musculoskeletal pain; Cycling athletes; Cycling; Physiotherapy.

\section{Resumen}

El ciclismo es una de las actividades más populares en todo el mundo y a pesar de ser considerada una modalidad de bajo impacto, algunos estudios indican que una postura inadecuada o la falta de preparación de los deportistas para esta práctica conllevan a lesiones musculoesqueléticas y dolor. En este sentido, el objetivo fue verificar, a partir de una revisión sistemática de la literatura, la prevalencia de dolor musculoesquelético en practicantes de ciclismo a partir de estudios encontrados en bases de datos en línea, publicados en los últimos diez años. Es un estudio exploratorio, cualitativo, del tipo de revisión sistemática. Para la recolección de datos se utilizó la metodología Proknow-C y para el análisis de los resultados se eligió el análisis descriptivo. Los resultados indican una alta prevalencia de dolor entre los ciclistas, siendo común el dolor en la columna lumbar, rodillas y miembros superiores e inferiores. Destacando la importancia de la Fisioterapia en el tratamiento y prevención de síntomas dolorosos que pueden verse agravados por la falta de asistencia especializada y ejercicios preventivos.

Palabras clave: Dolor musculoesqueléticas; Atletas ciclistas; Ciclismo; Fisioterapia. 


\section{Introdução}

$\mathrm{O}$ ato de pedalar tornou-se algo comum desde o século XIX tempo em que as bicicletas foram produzidas em excesso. Atualmente, o uso delas têm se tornado uma prática diária, devido aos benefícios físicos e incentivo por parte de diversos países e autoridades ambientais visando a redução da emissão de gases poluentes por veículos motorizados (Nunes \& Fonseca, 2017). A bicicleta, em sua maioria, é um veículo de baixo custo, fácil aquisição e manutenção, fato que corrobora para que ela seja utilizada para o lazer, como meio de transporte e também para a prática desportiva amadora e profissional, além de ser encontrada em centros de reabilitação e hospitais para tratamento de diversas doenças (Carvalho et al., 2017).

Contemporaneamente, o ciclismo é uma prática muito popular ao redor do mundo sendo realizada unicamente em cadeia cinética fechada, promove baixo impacto além da melhora da resistência, coordenação motora e atenção (Araújo \& Tomaz, 2013; Di Alencar et al., 2012; Carvalho et al., 2017). Embora todos os benefícios do esporte, quando o ciclista não está adaptado a uma rotina de treinos, não possui bons equipamentos ou não apresenta uma postura adequada na bicicleta, ele pode apresentar lesões que na maioria das vezes são classificadas como overuse termo em inglês utilizado para representar a utilização em excesso das estruturas osteomusculares (Alves, 2010; Nunes \& Fonseca, 2017).

Quanto às dores, se destacam algias no joelho e coluna vertebral lombar, são observadas lombalgias, compressão de nervos, bursites, tendinites, fascite plantar e outras (Alves, 2010; Pimentel \& Pires, 2011). A Fisioterapia é importante, nesse sentido, porque realiza um trabalho de reabilitação diminuindo as dores e processos inflamatórios, serve também como forma preventiva a possíveis lesões severas e/ou agudas (Martins, 2016; Nunes \& Fonseca, 2017).

Considera-se que o conhecimento sobre as dores e lesões osteomusculares ainda são limitadas. Sabe-se, porém, que distúrbios desencadeados pela prática do ciclismo é uma realidade que acomete parcela significativa dos atletas desse esporte, especialmente quando não possuem a preparação e acompanhamento profissional adequados que a modalidade requer. Devido a isso, o presente estudo tem como principal objetivo levantar a prevalência de dores osteomusculares em atletas e/ou praticantes de ciclismo a partir de estudos científicos já publicados, caracterizando-as, e refletindo sobre a importância da Fisioterapia.

A atenção ao papel do profissional de Fisioterapia, não somente no tratamento curativo, mas também no processo preventivo de dores e lesões osteomusculares em práticas esportivas, motivou este estudo e colaborou para a definição dos objetivos específicos: realizar levantamento da temática identificando-se as principais dores e lesões osteomusculares que afetam o ciclista; caracterizar e descrever os estudos encontrados; contribuir para a instrumentalização dos profissionais da área de fisioterapia a respeito da temática de estudo.

\section{Metodologia}

O estudo possui caráter exploratório e natureza qualitativa do tipo revisão sistemática da literatura. Utilizamos a pesquisa bibliográfica sistematizada, pois, é aquela que se utiliza de textos científicos já publicados como principal fonte de informação (Gil, 1996). E sistematizada, por requisitar uma sistematização do processo de busca dos materiais, formação de categorias, palavras-chaves e roteiros de busca, com posterior organização dos dados, leitura e análise dos conteúdos e ideias encontrada de maneira minuciosa e planejada, para verificar o estado do conhecimento científico em relação ao tema investigado (Gil, 1996; Marconi \& Lakatos, 2004).

Para tanto, optou-se pela utilização da metodologia ProKnow-C (Knowledge Development Process - Constructivist) para auxiliar o processo de organização da revisão sistemática, garantindo rigor e consistência metodológica ao processo de investigação (Afonso et al., 2011). A metodologia ProKnow-C foi desenvolvida pelo Laboratório de Metodologias Multicritério em Apoio à Decisão (LabMCDA), da Universidade Federal de Santa Catarina, e divide-se em quatro etapas: 1) seleção do portfólio bibliográfico que proporcionará a revisão de literatura; 2) análise bibliométrica do portfólio bibliográfico; 3) análise sistêmica do portfólio bibliográfico; 4) elaboração dos objetivos de pesquisa (Afonso et al., 2011). 
Para esse estudo optamos por seguir a metodologia ProKnow-C até a etapa de número três, considerando-se que os objetivos de pesquisa foram delimitados previamente. Nesse sentido, após a análise sistêmica do portfólio bibliográfico os dados foram analisados com base na análise descritiva do conteúdo.

O primeiro passo para realizar a seleção dos artigos, constituiu-se em definir as palavras-chaves, a escolha se deu a partir da definição do tema de pesquisa e dos objetivos do estudo. Em seguida foi feita a seleção dos bancos de dados e o teste de aderência dos termos de pesquisa, de modo a identificar se eram viáveis ao estudo ou se seria necessário redefini-los. Após o teste de aderência, os termos chaves para as buscas foram combinados utilizando-se o operador booleano (AND): dores osteomioarticulares; ciclismo; dores osteomiarticulares; ciclistas; atletas de ciclismo; lesões osteomusculares; cycling athletes; cycling; pain musculoskeletal; osteomyoarticular pain; musuloesketal pain;

Quanto aos bancos de dados, a escolha se deu pela adequação do conteúdo do banco à temática em questão. Assim, os bancos considerados foram os seguintes: Scielo, Pubmed, Scopus e Google Acadêmico. Posteriormente ao processo de busca dos artigos nas bases informadas, e devido ao baixo número de trabalhos encontrados, também foi incluída por critério de relevância para área da Fisioterapia a Plataforma PEDro. Na etapa seguinte, ocorreu o processo de filtragem do material selecionado contribuindo para uma maior coerência e adequação dos resultados.

O primeiro filtro utilizado delimitou o período de publicação dos artigos e trabalhos selecionados, nesse sentido foram considerados os últimos dez anos (2011 - 2021); o segundo, refere-se à eliminação de artigos repetidos, por conta do uso de diferentes combinações das palavras-chave; e por fim, leitura dos títulos, resumos e palavras-chave para verificar a pertinência dos estudos aos objetivos propostos.

Para identificar a relevância científica dos artigos selecionados, a partir dos títulos, foi realizada uma busca de citações no Google Acadêmico e com base nestas informações, calculou-se a representatividade de cada um desses artigos. A metodologia do ProKnow-C define que o ponto de corte seja em $85 \%$ do número de citações, entretanto, é possível que o pesquisador escolha os critérios mais adequados para sua pesquisa (Afonso et al., 2011). Estabeleceu-se, como ponto de corte o número igual ou superior a 5 citações, para a permanência dos artigos no portfólio, artigos recentemente publicados e ainda não citados foram mantidos, ora pela representatividade da revista, ora pela relevância para o estudo.

Após a realização dessas etapas encontramos 30 trabalhos, dentre os quais 10 foram selecionados para compor o portfólio de estudos da pesquisa. Artigos incompletos ou de revisão bibliográfica foram descartados das análises.

Tabela 1 - Quantidade de trabalhos encontrados nos bancos de dados.

\begin{tabular}{c|c}
\hline Banco de dados & Quantidade de trabalhos \\
\hline Scielo & 02 \\
\hline Google Acadêmico & 13 \\
\hline PUBMED & 05 \\
\hline Plataforma PEDro & 10 \\
\hline Total & 30 \\
\hline
\end{tabular}

Fonte: Autores (2021).

\section{Resultados e Discussões}

Encontramos 30 trabalhos referentes ao tema investigado, dentre esses 10 trabalhos foram selecionados para compor as análises. No corpus de análise, a maior parte é de estudos analíticos do tipo observacional $(n=7)$ e três do tipo experimental. Como instrumento de coleta de dados, a maioria utilizou questionário de sintomas osteomusculares, predominando o 
Questionário Nórdico já validado cientificamente e/ou adaptado, estes baseiam-se no autorrelato dos participantes que informam as regiões das queixas dolorosas e as possíveis causas.

Outro instrumento frequente foi a Escala Visual Analógica (EVA), que avalia o nível de dor através de uma linha com $10 \mathrm{~cm}$ de extensão contendo em suas extremidades as seguintes frases "ausência de dor" e "dor insuportável" (Carvalho et al., 2017). Observou-se em três estudos, a realização de testes físicos e experimentais específicos.

Os estudos apresentam uma variabilidade quanto aos participantes, dentre eles atletas profissionais, praticantes amadores e ciclistas que utilizam a bicicleta como instrumento de trabalho, como no estudo realizado por Pagani e Conserva (2015) e no estudo de Gama Filho et al. (2016) ambos realizados com carteiros-ciclistas. Prevaleceu entre os participantes dos estudos analisados o gênero masculino, o que pode ter relação com o uso da bicicleta ser maior entre os homens (27\%) em comparação ao gênero feminino (4,1\%0 (Bacchieri et al., 2005). A caracterização dos estudos encontra-se no Quadro 1.

Quadro 1 - Caracterização dos estudos encontrados no período de 2011 a 2021.

\begin{tabular}{|c|c|c|c|c|c|c|}
\hline Título & Autor/ano & Tipo de estudo & Amostra & Objetivo & $\begin{array}{l}\text { Instrumentos de } \\
\text { coleta de dados }\end{array}$ & Resultados \\
\hline $\begin{array}{l}\text { Sintomatologia } \\
\text { osteomuscular } \\
\text { dolorosa em } \\
\text { ciclistas noturnos } \\
\text { de Campina Grande } \\
\text { (PB) }\end{array}$ & $\begin{array}{l}\text { Araújo, P. B., } \\
\text { \& Tomaz, A. } \\
\text { F. (2014) }\end{array}$ & $\begin{array}{l}\text { Estudo analítico/ } \\
\text { transversal }\end{array}$ & $\begin{array}{l}83 \\
\text { participantes, } \\
\text { de ambos os } \\
\text { sexos, com } \\
\text { idades } \\
\text { variando entre } \\
18 \text { e } 50 \text { anos }\end{array}$ & $\begin{array}{l}\text { Verificar a presença de } \\
\text { sintomatologia } \\
\text { dolorosa } \\
\text { musculoesquelética } \\
\text { Em ciclistas noturnos } \\
\text { da cidade de Campina } \\
\text { Grande (PB). }\end{array}$ & \begin{tabular}{l}
\multicolumn{2}{l}{ Questionário } \\
Nórdico; Escala \\
Visual Analógica \\
(EVA) da dor; \\
questionário \\
sociodemográfic \\
o
\end{tabular} & $\begin{array}{lr}\begin{array}{l}\text { Observou-se } \\
\text { sintomatologia }\end{array} \\
\text { osteomuscular } \\
\text { dolorosa de nível } \\
\text { moderado } \\
\text { ciclistas nos } \\
\text { entrevistados, sendo } \\
25,3 \% \text { acometidos } \\
\text { por dor aguda, } 37,3 \% \\
\text { por dor crônica, e } \\
\text { afastamento de suas } \\
\text { atividades diárias } \\
\text { como Trabalho, } \\
\text { atividades domésticas } \\
\text { ou de lazer em } 43,4 \% \text {. }\end{array}$ \\
\hline $\begin{array}{l}\text { Distúrbios } \\
\text { osteomusculares } \\
\text { relacionados ao } \\
\text { trabalho em } \\
\text { carteiros ciclistas } \\
\text { da cidade de } \\
\text { Ariquemes, } \\
\text { Rondônia, Brasil. }\end{array}$ & 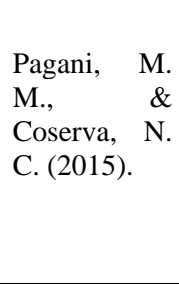 & $\begin{array}{l}\text { Estudo analítico, } \\
\text { observacional }\end{array}$ & $\begin{array}{l}05 \\
\text { participantes - } \\
03 \text { do sexo } \\
\text { masculino e } 02 \\
\text { do sexo } \\
\text { feminino. }\end{array}$ & $\begin{array}{l}\text { A incidência de } \\
\text { distúrbios } \\
\text { osteomusculares } \\
\text { relacionados } \\
\text { trabalho em carteiros } \\
\text { ciclistas }\end{array}$ & $\begin{array}{l}\text { Questionário } \\
\text { para levantar os } \\
\text { sintomas } \\
\text { dolorosos e } \\
\text { avaliação física. }\end{array}$ & $\begin{array}{l}50 \% \text { apresentaram } \\
\text { Dor/desconforto na } \\
\text { coluna torácica; } 25 \% \\
\text { no pescoço, nos } \\
\text { ombros e punhos }\end{array}$ \\
\hline $\begin{array}{l}\text { Prevalência de } \\
\text { sintomas } \\
\text { osteomusculares } \\
\text { em praticantes de } \\
\text { Mountain bike }\end{array}$ & $\begin{array}{l}\text { Carvalho, T. } \\
\text { S. et al. } \\
(2017)\end{array}$ & $\begin{array}{l}\text { Estudo analítico, } \\
\text { descritivo, } \\
\text { transversal }\end{array}$ & $\begin{array}{l}30 \text { ciclistas do } \\
\text { gênero } \\
\text { masculino } \\
\text { entre } 18 \text { e } 59 \\
\text { anos. }\end{array}$ & $\begin{array}{l}\text { Identificar os sintomas } \\
\text { osteomusculares } \\
\text { prevalentes em } \\
\text { praticantes da Mountain } \\
\text { Bike }\end{array}$ & $\begin{array}{l}\text { Questionário } \\
\text { Nórdico; Escala } \\
\text { Visual Analógica } \\
\text { (EVA) da dor; } \\
\text { questionário } \\
\text { sociodemográfic } \\
\text { o }\end{array}$ & $\begin{array}{l}\text { A sintomatologia } \\
\text { osteomuscular mais } \\
\text { prevalente é a } \\
\text { dolorosa, sendo as } \\
\text { regiões rais } \\
\text { comprometidas a } \\
\text { lombar e os membros } \\
\text { inferiores. }\end{array}$ \\
\hline $\begin{array}{l}\text { Avaliação } \\
\text { fisioterapêutica no } \\
\text { ciclismo: } \quad \text { um } \\
\text { estudo de caso. }\end{array}$ & $\begin{array}{l}\text { Martins, A. } \\
\text { S. et al. } \\
(2016)\end{array}$ & Estudo de caso & $\begin{array}{l}1 \text { paciente. } \\
27 \text { anos }\end{array}$ & $\begin{array}{l}\text { Descrever sobre a } \\
\text { Avaliação funcional de } \\
\text { um ciclista que } \\
\text { apresentava sintomas } \\
\text { de formigamentos em } \\
\text { Membros superiores e } \\
\text { inferiores }\end{array}$ & $\begin{array}{l}\text { Testes funcionais } \\
\text { como o FMS, } \\
\text { Bunkie Test, } \\
\text { Single Leg Squat; } \\
\text { Avaliação } \\
\text { isocinética e } \\
\text { avaliação do } \\
\text { gesto esportivo } \\
\text { em wattsbike. }\end{array}$ & $\begin{array}{l}\text { Forte relação entre o } \\
\text { desequilíbrio } \\
\text { Muscular encontrado } \\
\text { no exame isocinético } \\
\text { e no exame feito com } \\
\text { a wattsbike com a } \\
\text { Fadiga relatada pelo } \\
\text { paciente. }\end{array}$ \\
\hline $\begin{array}{lr}\text { Prevalência } & \mathrm{de} \\
\text { lesões } & \mathrm{em} \\
\text { praticantes } & \mathrm{de} \\
\text { ciclismo indoor } & \end{array}$ & $\begin{array}{l}\text { Rienda, A. } \\
\text { S., Moreira, } \\
\text { R. A., de } \\
\text { Oliveira } \\
\text { Castro, H., \& } \\
\text { de Oliveira } \\
\text { Pires, F. } \\
\text { (2012). }\end{array}$ & $\begin{array}{l}\text { Estudo } \\
\text { experimental }\end{array}$ & $\begin{array}{l}150 \text { indivíduos } \\
\text { de ambos os } \\
\text { sexos; media } \\
\text { de idade de } \\
31,3 \quad(10,7) \\
\text { anos. }\end{array}$ & $\begin{array}{lr}\text { Levantar } & \text { Dados } \\
\text { científicos no } & \text { ciclismo } \\
\text { indoor } & \end{array}$ & $\begin{array}{l}\text { Questionario } \\
\text { Nordico de } \\
\text { Sintomas } \\
\text { Osteomusculares } \\
\text {. }\end{array}$ & 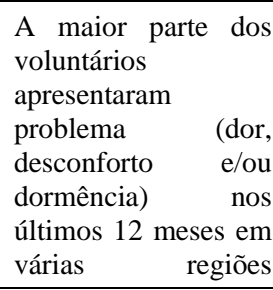 \\
\hline
\end{tabular}




\begin{tabular}{|c|c|c|c|c|c|c|}
\hline & & & & & & $\begin{array}{l}\text { anatômicas do } \\
\text { membro superior e do } \\
\text { membro inferior }\end{array}$ \\
\hline $\begin{array}{l}\text { A prevalência de } \\
\text { lesões } \\
\text { osteomioarticulares } \\
\text { em ciclistas } \\
\text { amadores }\end{array}$ & $\begin{array}{ll}\text { Fonseca, } & \text { P. } \\
\text { D. S., } & \text { \& } \\
\text { Nunes, } & \text { K. } \\
\text { (2017). } & \end{array}$ & Experimental & $\begin{array}{ll}52 \text { ciclistas } & \text { de } \\
\text { ambos } & \text { os } \\
\text { gêneros. } & \\
\text { Idades entre } & 20 \\
\text { e } 60 \text { anos. }\end{array}$ & $\begin{array}{l}\text { Avaliar a prevalência de } \\
\text { lesões } \\
\text { osteomioarticulares em } \\
\text { um grupo de ciclistas } \\
\text { amadores residentes em } \\
\text { Astorga/PR }\end{array}$ & $\begin{array}{l}\text { Inventário de Dor } \\
\text { de Becker }\end{array}$ & $\begin{array}{l}\text { A dor não foi } \\
\text { predominante entre } \\
\text { os participantes da } \\
\text { prática de ciclismo, } \\
\text { porém estes que a } \\
\text { referiram }(32,7 \%),\end{array}$ \\
\hline $\begin{array}{l}\text { Prevalência de } \\
\text { lesões músculo- } \\
\text { esqueléticas em } \\
\text { ciclistas }\end{array}$ & $\begin{array}{l}\text { Fortuna, P. et } \\
\text { al. (2017) }\end{array}$ & $\begin{array}{l}\text { Estudo } \\
\text { observacional, } \\
\text { inferencial, } \\
\text { transversal. }\end{array}$ & $\begin{array}{l}30 \text { ciclistas. } \\
\text { Idades entre } 20 \\
\text { e } 65 \text { anos. }\end{array}$ & $\begin{array}{l}\text { Determinar a } \\
\text { prevalência de lesões } \\
\text { músculo-esqueléticas } \\
\text { nos ciclistas } \\
\text { profissionais } \\
\text { amadores, } \\
\text { relacionando-a com as } \\
\text { características } \\
\text { individuais de trabalho. }\end{array}$ & $\begin{array}{l}\text { Questionário } \\
\text { nórdico músculo- } \\
\text { esquelético }\end{array}$ & $\begin{array}{lr}\text { As regiões } \\
\text { anatómicas r com } \\
\text { maior prevalência de } \\
\text { lesões músculo- } \\
\text { esqueléticas, por } \\
\text { ordem decrescente, } \\
\text { foram a lombar, os } \\
\text { joelhos, o pescoço, as } \\
\text { ancas e os ombros a a } \\
\text { nível da intensidade } \\
\text { dor os joelhos, a } \\
\text { lombar, o pescoço, as } \\
\text { ancas e os ombros } \\
\text { MM. }\end{array}$ \\
\hline $\begin{array}{ll}\text { Prevalência } & \text { de } \\
\text { lesão em atletas } & \text { de } \\
\text { ciclismo } & \text { de } \\
\text { mountain bike } & \end{array}$ & $\begin{array}{l}\text { Torres et al. } \\
(2020)\end{array}$ & $\begin{array}{l}\text { Estudo } \\
\text { epidemiológico } \\
\text { transversal } \\
\text { observacional }\end{array}$ & $\begin{array}{l}100 \\
\text { participantes } \\
\text { de ambos os } \\
\text { sexos. } \\
\text { Idades entre } 18 \\
\text { e } 45 \text { anos. }\end{array}$ & $\begin{array}{l}\text { Analisar a prevalência } \\
\text { de lesões } \\
\text { musculoesqueléticas } \\
\text { relacionadas à membro } \\
\text { inferior em atletas de } \\
\text { ciclismo do Estado de } \\
\text { Alagoas. }\end{array}$ & $\begin{array}{l}\text { Questionário } \\
\text { estruturado }\end{array}$ & $\begin{array}{l}\text { Houve a maior } \\
\text { ocorrência de lesões } \\
\text { nos praticantes de } \\
\text { mountain bike, } \\
\text { principalmente } \\
\text { ocasionadas por } \\
\text { quedas. Aqueles que } \\
\text { relataram dor tiveram } \\
\text { maior prevalência de } \\
\text { lesões em relação } \\
\text { aqueles sem dor. }\end{array}$ \\
\hline $\begin{array}{l}\text { Time-course of } \\
\text { changes in indirect } \\
\text { markers of muscle } \\
\text { damage responses } \\
\text { following a 130-km } \\
\text { cycling race }\end{array}$ & $\begin{array}{l}\text { Rodrigues et } \\
\text { al. (2016) }\end{array}$ & $\begin{array}{l}\text { Estudo } \\
\text { experimental }\end{array}$ & $\begin{array}{l}15 \text { ciclistas do } \\
\text { sexo } \\
\text { masculino; } \\
\text { Média de idade } \\
27,5\end{array}$ & $\begin{array}{l}\text { Identificar os efeitos de } \\
\text { uma corrida de ciclismo } \\
\text { de } 130 \mathrm{~km} \text { nos índices } \\
\text { de marcadores } \\
\text { bioquímicos indiretos } \\
\text { de lesão muscular e } \\
\text { respostas de dor } \\
\text { muscular durante um } \\
\text { período de recuperação } \\
\text { de } 72 \text { horas. }\end{array}$ & $\begin{array}{l}\text { Questionário de } \\
\text { histórico de de } \\
\text { saúde e um } \\
\text { Questionário de } \\
\text { prontidão para } \\
\text { atividade física } \\
\text { (PAR-Q); Escala } \\
\text { Visual Analógica } \\
\text { (VAS) }\end{array}$ & $\begin{array}{l}\text { Uma corrida de } \\
\text { ciclismo de } 130 \mathrm{~km} \\
\text { tem um efeito notável } \\
\text { nos índices de } \\
\text { marcadores } \\
\text { bioquímicos indiretos } \\
\text { de lesão muscular e } \\
\text { dor muscular. }\end{array}$ \\
\hline $\begin{array}{l}\text { Avaliação do ajuste } \\
\text { do selim } \quad \text { e } \\
\text { percepção de dor } \\
\text { em ciclistas } \\
\text { prestadores de } \\
\text { serviços postais }\end{array}$ & $\begin{array}{l}\text { Gama Filho, } \\
\text { A. S. et al. } \\
\text { (2016) }\end{array}$ & Estudo de campo & $\begin{array}{l}17 \\
\text { participantes } \\
\text { do sexo } \\
\text { masculino. }\end{array}$ & $\begin{array}{l}\text { Identificar a } \\
\text { prevalência de } \\
\text { desajustes da altura do } \\
\text { selim e sua associação } \\
\text { com incidência } \\
\text { de dores corporais em } \\
\text { prestadores de serviços } \\
\text { postais. }\end{array}$ & $\begin{array}{l}\text { escala de } \\
\text { percepção } \\
\text { subjetiva e altura } \\
\text { do selim por } \\
\text { biofotogrametria } \\
\text { do ângulo de } \\
\text { flexão do joelho }\end{array}$ & $\begin{array}{l}\text { A amostra estudada } \\
\text { possui alta } \\
\text { prevalência de queixa } \\
\text { de dores e } 76,4 \% \\
\text { estavam com a altura } \\
\text { do selim inadequada. }\end{array}$ \\
\hline
\end{tabular}

Fonte: Autores (2021).

As modalidades de ciclismo encontradas nos estudos foram: ciclismo indoor; mountain bike; ciclismo de rua e ciclismo de rendimento. A literatura relata a popularização das diferentes modalidades do ciclismo na população brasileira que tem demonstrado adesão às diversas modalidades existentes, justificando-se o interesse de pesquisadores em investigar sintomas osteomusculares associados à uma maior variedade de práticas de ciclismo.

Os estudos demonstram que as dores mais prevalentes entre os ciclistas são: dor na coluna lombar, nos joelhos, nos membros inferiores (coxa e perna) e nos membros superiores (ombros, punhos, pescoço). Outros estudos com ciclistas já relataram que as regiões que mais sofrem danos são os joelhos, seguido pelas nádegas, e membros superiores (MMSS) como as mãos, levando também à disfunção da coluna vertebral lombar (Pimentel \& Pires, 2011). Nesse sentido, a literatura indica que 
as lesões e sintomas osteomusculares no ciclismo podem ser globais, acometendo membros superiores e membros inferiores, corroborando com o encontrado neste estudo.

Ainda de acordo com os estudos analisados, as dores acometem com maior frequência o sexo masculino, contudo não há indícios suficientes que comprovem a relação da prevalência de dores relacionado ao gênero, carecendo de estudos que analisem especificamente a questão. Esse resultado pode relacionar-se com o fato do sexo masculino predominar entre os ciclistas participantes dos estudos analisados, o que reflete a tendência do ciclismo ser um esporte popular entre o gênero masculino (Bacchieri et al., 2005).

Observa-se que as causas das dores são variadas, aparecendo com maior frequência aquelas relacionadas à ergonomia, como postura inadequada do atleta e altura do selim. Outro motivo frequente refere-se a dores causadas por fadiga muscular e fraqueza muscular. Chagas (2015) já havia relatado que os motivos intrínsecos para a alta prevalência de dor lombar em ciclistas decorre da fraqueza muscular e/ou fadiga da região do lombo-pélvico (core). Surgiram também causas de dores associadas ao estilo de vida e ao tempo de prática. Em dois estudos não foram relatadas as causas das dores nos participantes.

Esses resultados conferem com resultados obtidos em estudos anteriores, os quais retratam que os danos podem ser causados por diversos fatores que vão desde o ambiente onde o ciclista pedala, e/ou falta de equipamentos adequados (fatores externos) a fatores do próprio corpo (fatores intrínsecos), como a postura incorreta, falta de preparo físico, prejudicando o desempenho esportivo, provocando dores e lesões, o afastamento dos treinos e a dificuldade em realizar atividades de vida diária (Alves, 2010; Chagas, 2015).

Na maioria dos estudos analisados há a recomendação da realização de tratamento através do desenvolvimento de programas de exercícios preventivos e fisioterapêuticos sob a orientação profissional do fisioterapeuta, apenas um estudo não previu e/ou indicou tratamento. Esse resultado reforça a importância da Fisioterapia no trato dos sintomas osteomusculares no ciclismo, já previamente alertada por diferentes autores como Alves, 2010; Chagas, 2015; Lima, 2018; Pimentel e Pires, 2011.

A intervenção profissional pode ser realizada desde o momento em que a lesão começa a ser instalada, até o momento que ocorre sequelas teciduais; é através do diagnóstico fisioterapêutico que se elaboram condutas para que o ciclista apresente uma melhor recuperação e possa voltar de forma mais rápida aos treinos (Alves, 2010; Fortuna, 2017). A fisioterapia também realiza programas preventivos ao ensinar técnicas de alongamentos para serem realizadas antes e após os treinos, incluindo a adaptação da bicicleta à anatomia do corpo do indivíduo (Lima, 2018).

Sabe-se que a posição ao pedalar não é algo natural do ser humano, podendo ocasionar dores e lesões osteomioarticulares (Cunha et al., 2017; Pimentel \& Pires 2011). Segundo Pimentel e Pires (2011) as regiões que mais sofrem danos são os joelhos, seguido pelas nádegas, e membros superiores (MMSS) como as mãos, levando também à disfunção da coluna vertebral lombar, ocasionada pelos treinos incorretos ou falta de adaptação da bicicleta, entre outros fatores.

No estudo de Araújo e Tomáz (2013) verificou-se a prevalência de dor nos membros superiores e inferiores e uma tendência ao afastamento das atividades de vida diária nos últimos 12 meses, com maior incidência no sexo masculino. Para a associação da presença de dor com as variáveis sexo, estado civil e escolaridade acima de 12 anos, não foi observada significância, sugerindo que tais características não interferem nas dores relatadas.

Nesse mesmo estudo, a associação entre as variáveis da prática do ciclismo e a presença de dor apresentaram significância apenas para o alongamento pós-atividade e o ajuste da bicicleta, reiterando o exposto por Lima (2018). Notou-se que a maioria dos ciclistas $(66,3 \%)$ realizava alongamentos antes das atividades, mas após o término $63 \%$ não os executavam, além disso, 42,2\% da amostra estavam com sobrepeso, 18,1\% com obesidade e apenas 16,9\% dos indivíduos apresentaram queixas de lesão (Araújo \& Tomáz, 2013).

Os resultados do estudo de Pagani e Conserva (2015) ao investigarem a incidência de distúrbios osteomusculares relacionados ao trabalho em carteiros ciclistas, apontam que 50\% deles apresentavam dor na coluna torácica, 25\% nas mãos e 
outros 25\% nos punhos. Resultado que diverge do encontrado por Gama Filho et al. (2016), em estudo também realizado com carteiros ciclistas, prevalecendo neste grupo as dores na coluna vertebral $(47,06 \%)$ e nos joelhos $(35,29 \%)$.

Ressalta-se que no estudo de Pagani e Conserva (2015) as causas foram atribuídas ao tempo que os carteiros-ciclistas passavam na bicicleta, já no estudo de Gama Filho et al. (2016) além das queixas dolorosas, foi verificada a altura do selim da bicicleta de cada carteiro, comprovando-se a relação entre a altura do selim inadequada e a incidência de dores, comprovandose a influência de fatores externos na manifestação de dores, algo bastante reportado na literatura (Chagas, 2015; Cunha et al., 2017; Pimentel \& Pires 2011).

Em contraponto aos estudos de Pagani e Conserva (2015) e Gama Filho et al. (2016), no estudo de Fortuna et al. (2017) investigou-se a relação entre a queixa de dores e a relação com o tipo de trabalho desempenhado por 30 ciclistas profissionais e amadores. Os resultados indicaram que não há correlação entre o trabalho individual desempenhado e a dor relatada. No entanto, as regiões anatômicas com maior prevalência de lesões assemelham-se aos resultados dos estudos anteriores, prevalecendo a maior incidência na lombar, nos joelhos, no pescoço, nas ancas e nos ombros, porém a nível da intensidade da dor, prevaleceu os joelhos, a lombar, o pescoço, as ancas e os ombros, respectivamente.

Ainda no estudo de Fortuna et al. (2017) observou-se que a dor na lombar (13,30\%), nos pés (16,70\%) e nos joelhos (20\%) foram as maiores causas da limitação e/ou afastamento nas atividades da vida diária nos últimos 12 meses, corroborando com o estudo de Araújo e Tomáz (2013).

Praticantes de ciclismo com incidência de dor retrospectiva possuem maiores chances de desenvolverem lesões traumáticas, a probabilidade é de 48,8\% enquanto para os sem dor é de $20 \%$ (Torres et al., 2020). Corroborando com o estudo de Rienda et al. (2012), no qual observou-se que as lesões mais frequentes em 52 praticantes de ciclismo indoor, foram na região lombar e nos joelhos. Essas regiões também obtiveram maiores índices de dor, desconforto e ou dormência relatada, já nos membros superiores prevaleceu a dor na lombar $(28,8 \%)$ e nos membros inferiores a região dos joelhos e perna, ambos com $26,9 \%$.

Rienda et al. (2021) relacionam os sintomas dolorosos relatados no estudo com a má postura dos ciclistas ao sentarem no selim da bicicleta, o que acaba resultando em carga excessiva na região da coluna lombar e maior requisição da articulação do joelho ao executarem o movimento da pedalada. Em contraponto, o estudo de Martins et al. (2016) ao realizarem avaliação funcional em um ciclista do sexo masculino com quadro de dor e formigamento nos membros inferiores, observaram rápida fadiga muscular nos posteriores da coxa, especialmente ao treinar usando bicicleta do tipo estrada, já o formigamento era comum após moderado tempo pedalando mountain bike.

Contudo, o ciclista participante do estudo, possuía bons hábitos de vida, além do acompanhamento nutricional e fisioterapêutico, divergindo da maioria dos estudos em que raramente os ciclistas possuem acompanhamento profissional ou a preocupação em realizar avaliação fisioterapêutica (Torres et al., 2020). Nesse sentido, os autores concluíram, a partir de uma série de testes realizados, que o paciente possuía um desequilíbrio muscular entre o quadríceps e os isquiotibiais em ambos os membros inferiores e isso acometia os sintomas dolorosos e a rápida fadiga muscular afetando seu desempenho (Martins $e t$ al., 2016).

Contudo, em Nunes e Fonseca (2017) os resultados da investigação com 52 ciclistas de ambos os gêneros que não possuíam assistência de profissional de saúde, demonstraram que a dor não foi predominante entre os participantes; mas na parcela que a relatou $(32,7 \%)$, todos eram tabagistas, sugerindo-se relação entre o estilo de vida e a existência de dor. Comparando-se os resultados obtidos por Martins et al. (2016) e por Nunes e Fonseca (2017) sugere-se a realização de estudos mais amplos para avaliar a significância da relação entre a incidência de dor e o estilo de vida dos praticantes de ciclismo, relação ainda escassa na literatura.

Carvalho et al. (2017) concluíram em estudo realizado com 30 ciclistas de mountain bike, que a sintomatologia osteomuscular mais prevalente é a dolorosa, sendo a coluna lombar e membros inferiores as regiões mais acometidas por dor, 
corroborando com os demais estudos analisados nesse estudo. Resultado que também é semelhante ao de Torres et al. (2020) que investigou a prevalência de lesões em 100 praticantes de ciclismo, a maioria da modalidade mountain bike, com idades entre de 18 a 45 anos, os resultados indicaram a coluna lombar e joelhos como as áreas mais afetadas por dor.

Sabe-se que o intervalo entre um estímulo e outro durante a realização de exercícios físicos é necessário à recuperação das estruturas anatômicas envolvidas, especialmente para a cicatrização dos microtraumas que ocorrem nos tecidos musculares. No ciclismo de resistência os danos musculares, a fadiga e dores são frequentes em virtude da carga excessiva imposta pelos treinos e competições (Torres et al., 2020).

Nesse sentido, o estudo de Rodrigues et al. (2016), submeteu 15 atletas de ciclismo de resistência a testes de marcadores bioquímicos indiretos antes e imediatamente após corridas de $130 \mathrm{~km}$, para avaliar lesões musculares e respostas de dor muscular. Observaram que o início tardio de dor muscular pós-corrida aumentou significativamente, normalizando somente após 48 horas. Para os autores, 72 horas não são suficientes para a recuperação do atleta de ciclismo de resistência, sendo necessário conhecer o comportamento desses biomarcadores para melhorar o desempenho dos atletas, a qualidade de vida e prevenir lesões.

Dessa maneira, observa-se que a prevalência de dores em ciclistas de diferentes modalidades possui causas diferenciadas, porém atreladas a fatores externos e intrínsecos, como por exemplo a altura do selim da bicicleta e/ou a postura errônea do atleta ao executar a pedalada, sendo com frequência as regiões da coluna lombar e do joelho as mais afetadas, conforme o encontrado no presente estudo. Além disso, também é alta a prevalência de dores nos membros superiores e membros inferiores, provocando lesões e transtornos tanto para o desempenho atlético quanto para a saúde e bem-estar dos ciclistas.

\section{Considerações Finais}

O ciclismo é uma prática comum na atualidade havendo diferentes modalidades e adesão acentuada na população. O desempenho obtido por seus praticantes pode sofrer interferências de fatores ambientais, biomecânicos, mecânicos e humanos, já que a posição necessária para a realização da pedalada requer a adoção de uma postura não habitual ao ser humano e a prática recorrente e/ou estímulos excessivos podem acarretar em sintomas osteomusculares.

Com base nos estudos analisados, observou-se que a prevalência de sintomas osteomusculares dolorosos é alta nos ciclistas, sendo comum as dores na coluna lombar, joelhos e membros superiores (mãos, punho, pescoço) e inferiores (coxa e perna), estando associadas a aspectos ergonômicos e falta de exercícios preventivos, corroborando com a literatura. Raramente os estudos analisados reportam ausência de dor entre os praticantes de ciclismo.

Nesse sentido, os estudos compartilham a recomendação da realização de exercícios preventivos e fisioterapêuticos sob a orientação profissional, ressaltando a importância da Fisioterapia e necessidade da avaliação fisioterapêutica, seja no tratamento ou na prevenção de sintomas dolorosos, os quais podem ser agravados pela falta de assistência especializada e de exercícios preventivos.

Sugerimos a realização de novos estudos com enfoque na investigação das causas e associações entre a presença de dor e variáveis como estilo de vida, gênero e modalidade, visando a construção de conhecimentos que contribuam para o desenvolvimento de programas e condutas preventivas, tanto para a melhoria do desempenho, quanto da qualidade de vida dos praticantes de ciclismo.

\section{Referências}

Afonso, M. H., Souza, J. D., Ensslin, S. R., \& Ensslin, L. (2011). Como construir conhecimento sobre o tema de pesquisa? Aplicação do processo Proknow-C na busca de literatura sobre avaliação do desenvolvimento sustentável. Revista de Gestão Social e Ambiental , 5 (2), 47-62. DOI: 10.5773/rgsa.v5i2.424

Alves, E.G. (2010). Análise das respostas EMG lombar e de membros inferiores em dois diferentes ajustes no ângulo do selim em ciclista de rua durante a pedalada. [Monografia de Especialização em Fisioterapia Traumato Ortopédica e Desportiva, Universidade do Extremo Sul de Santa Catarina] Repositório Digital Unesc. http://repositorio.unesc.net/bitstreamhandle/1/944/Eduardo\%20Garcia\%20Alves.pdf?sequence=1. 
Araújo, P. B., \& Tomaz, A. F. (2014). Sintomatologia osteomuscular dolorosa em ciclistas noturnos de campina grande (pb). TEMA-Revista Eletrônica de Ciências (ISSN 2175-9553), 14(20; 21). http://revistatema.facisa.edu.br/index.php/revistatema/article/view/170.

Bacchieri, G., Gigante, DP, \& Assunção, MC (2005). Determinantes e padrões de utilização da bicicleta e acidentes de trânsito sofridos por ciclistas trabalhadores da cidade de Pelotas, Rio Grande do Sul, Brasil. Cadernos de Saúde Pública, 21, 1499-1508. https://www.scielosp.org/article/ssm/content/raw/?resource_ssm_path=/media/assets/csp/v21n5/23.pdf

Carvalho, T. S., Ferreira, J. B., de Amorim, J. F., de Jesus Lima, M., \& de Morais, K. C. S. (2017). Prevalência de sintomas osteomusculares em praticantes de mountain bike. Revista InterScientia, 5(1), 189-203. https://periodicos.unipe.edu.br/index.php/interscientia/article/view/490

Cunha, A.; Campos, R. M.; Silva, C. N.; Trennepohl, C.; Kellermann, M.; Paula, A. C.; \& Keller, K. D. (2017). A biomecânica do ciclismo: uma revisão de literatura. XXII Seminário Interinstitucional de Pesquisa e Extensão Unicruz. https://home.unicruz.edu.br/seminario/anais/anais.

Chagas, T. P. (2015). Dor lombar em ciclistas. [Trabalho de Conclusão de curso apresentado ao programa de Especialização em Fisioterapia Esportiva, Universidade Federal de Minas Gerais] Repositório Institucional da UFMG. https://repositorio.ufmg.br/handle/1843/BUBD-AELJQW

Alencar, T. A. M., de Sousa Matias, K. F., \& do Couto Aguiar, B. Lesões Agudas em Ciclistas. (2012). Revista Movimenta ISSN, 5(3). http://www.studiobikefit.com.br/wa_files/lesoes\%20agudas\%20em\%20ciclistas.pdf

Fonseca, P. D. S., \& Nunes, K. (2017). A prevalência de lesões osteomioarticulares em ciclistas amadores. [Trabalho de Conclusão de Curso, Unicesumar] Repositório Digital Unicesumar. http://rdu.unicesumar.edu.br/handle/123456789/394

Fortuna, P. Cervaens, M.; \& Pereira, R. (2017). Prevalência de lesões músculo-esqueléticas em ciclistas. [Bachelor's thesis, Universidade de Fernando Pessoa, Porto] Repositório Institucional da Universidade Fernando Pessoa. https://bdigital.ufp.pt/handle/10284/6287

Gama Filho, A. S., Pereira, E. N. S., Teixeira, G. P., Rocha, J. Q., Henrique, T. F., \& da Silva, V. G. (2018). Avaliação do ajuste do selim e percepção de dor em ciclistas prestadores de serviços postais. Seminário Transdisciplinar da http://periodicos.univag.com.br/index.php/SeminSaude/article/viewFile/908/1086

GIL, A. C. (2008). Métodos e técnicas de pesquisa. Atlas S.A.

Lima, B. I. R. S. (2018). Efeitos da fisioterapia preventiva em atletas: uma revisão bibliográfica. [Trabalho de Conclusão de Curso, Universidade Federal da Paraíba, João Pessoa] Repositório da Universidade Federal da Paraíba. https://repositorio.ufpb.br/jspui/handle/ Universidade Federal da Paraíba $123456789 / 12530$.

Marconi, M.A. \& Lakatos, E.M. (2004). Metodologia Científica. $4^{\text {a }}$. ed. Atlas.

Martins, A. S., Santos, M. G. R. D., Souza Junior, J. R., \& Lemos, T. V. (2016). Avaliação fisioterapêutica no ciclismo: um estudo de caso. Revista de Trabalhos Acadêmicos-Universo-Goiânia.

Pagani, M. M., \& Coserva, N. C. (2015). Distúrbios osteomusculares relacionados ao trabalho em carteiros ciclistas da cidade de Ariquemes, Rondônia, Brasil. Revista Educação, Cultura Sociedade, 5(1). https://web.archive.org/web/20180416024129id_http://sinop.unemat.br/projetos/revista/index.php/educacao/article/viewFile/1768/1556

Pimentel, S. \& Pires F (2011). Lesões crónicas do joelho em ciclistas. Revista da Sociedade Portuguesa de Medicina Física e de Reabilitação, 20(1).

Rienda, A. S., Moreira, R. A., de Oliveira Castro, H., \& de Oliveira Pires, F. (2012). Prevalência de lesões em praticantes de ciclismo indoor. Lecturas: Educación física y deportes, (170), 8-10. https://dialnet.unirioja.es/servlet/articulo?codigo $=4742037$

Rodrigues, P., Wassmansdorf, R., Salgueirosa, FM, Hernandez, SG, Nascimento, VB, Daros, LB, ... \& Osiecki, R. (2016). Time-course of changes in indirect markers of muscle damage responses following a 130-km cycling race. Revista Brasileira de Cineantropometria \& Desempenho Humano, 18, $322-331$. https://www.scielo.br/j/rbcdh/a/7bFgsC9z48CSXzswFwqLMDB/?lang=en

Torres, C. M., \& Souza, D. L. C. D. (2020). Prevalência de lesão em atletas de ciclismo de Mountain Bike. [Trabalho de Conclusão de Curso, Centro Universitário Tiradentes] Repositório Interinstitucional Tiradentes. http://openrit.grupotiradentes.com:8080/xmlui/handle/set/3789 